\title{
The Analysis of The Cable Crane In The Large Span Bridge

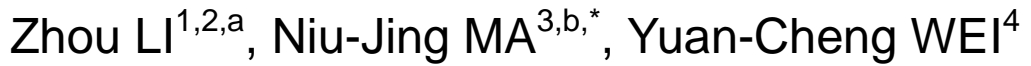 \\ ${ }^{1}$ China Construction Steel Structure Corp.Ltd, Guangdong, China \\ ${ }^{2}$ Hunan University, Hunan, China \\ ${ }^{3}$ South China University of Technology, Guangdong \\ ${ }^{4}$ Dalang Subdistrict office of Shenzhen Longhua District, China \\ a1203220423@qq.com, bchenmu07040327@sina.com \\ "Corresponding author
}

Keywords: The Cable Crane, The Track Cable, The Hoisting Cable.

\begin{abstract}
Jinsha river bridge is the biggest span suspension bridge under construction across the canyon. The analysis of the cable crane is of vital importance. The parabola theory of three spans is used in this paper to design the selection and installation of the sag of the track cable and hoisting cable. At last, the result is used to guide the design of the structure. The calculation results can provide the reference to the design of cable crane in the large span bridge in the future.
\end{abstract}

\section{Introduction}

The main part of Jinsha river bridge is a twin towers suspension bridge. The mainspan is $1386 m$ and rise-span ratio is $1 / 10$. The theoretical spans is $330 m+1386 m+205 m$. The horizontal distance between main cable is $27 \mathrm{~m}$. The theoretical sag of the main cable in the mid-span is $138.6 \mathrm{~m}$. Cable crane hoisting is used for the main girder construction. The direction of the erection is from the mid-span to both side of the bridge. The beam is divided to 127 sections that contains 124 standard beam sections and 3 special beam sections. The length of the standard beam section is $10.8 \mathrm{~m}$.

In order to ensure the safety and construction schedule in the process of hoisting construction of the main beam, it is using the scheme of the cable crane. The theoretical lifting capacity is $150 t$.

M.X. Ran and H.S. Xu[2] worked on the design of the cable crane of the Beipan River Bridge based on the three spans parabola theory. X.G. Li e.t.[3] introduced the cable crane applicated in the Qingshui River Bridge. As the first cable crane in the thousand meter scale, the project solved many problems. X.T. Deng e.t.[4] put their attention on the finite element analysis on the Wujiang River in the Pengshui city. G.R. Zheng e.t.[5] analyzed the characteristics of cable crane. The process itself of the economy, the construction efficiency, process maturity are analyzed in their study. W.D. Liu e.t.[6] optimized the details of the bridge design. J. Yao[7] introduced the situation of the construction of the Sidu River Bridge. S.Z. Yang e.t.[8] summarizes the construction design process of the cable crane of the Egongyan Suspension Bridge.

\section{The Design of The Cable Crane}

\section{The Overall Design}

The mid-span of the cable crane is $1380 \mathrm{~m}$. It is consist of the anchorage, the tower, the track cable, the hoisting cable and the pulling cable. 


\section{The design of the track cable}

Because of the reason that the span of the Jinsha river bridge is relatively large and the terrain and environment are complex, the traditional calculation formula of the track cable based on the theory of the single span parabola can not meet the needs of construction precision and it need further study. Hongsheng Xu e.t.[1] took all the three span into consideration and got the state equations of the track cable tension, as shown in Equs.(1) and (2)

$$
H_{x}^{3}+a H_{x}^{2}-b=0
$$

Where

$$
\begin{aligned}
& a=\frac{E_{k} A \cos ^{3} \beta}{24 K_{1} H_{\max }^{2}}\left(K_{1}+K_{2}\right)-H_{\text {max }} \\
& -\varepsilon \Delta t E_{k} A \cos \beta \\
& b=\frac{E_{k} A \cos ^{3} \beta}{24 K_{1}}\left[K_{4}\right. \\
& \left.+\frac{12(L-x) x}{L \cos ^{2} \beta} Q_{x}\left(Q_{x}+K_{5}\right)\right] \\
& K_{1}=\frac{L_{1}}{\cos \beta_{1}}+\frac{L}{\cos \beta}+\frac{L_{3}}{\cos \beta_{3}} \\
& K_{2}=\frac{3 Q_{\max }^{2} L}{\cos ^{2} \beta}+\frac{3 Q_{\max } q L^{2}}{\cos ^{3} \beta} \\
& K_{3}=\frac{q_{1}^{2} L_{1}^{3}}{\cos ^{4} \beta_{1}}+\frac{q^{2} L^{3}}{\cos ^{4} \beta}+\frac{q_{2}^{2} L_{2}^{3}}{\cos ^{4} \beta_{2}} \\
& K_{4}=\frac{q_{x 1}^{2} L_{1}^{3}}{\cos ^{4} \beta_{1}}+\frac{q_{x}^{2} L^{3}}{\cos ^{4} \beta}+\frac{q_{x 2}^{2} L_{2}^{3}}{\cos ^{4} \beta_{2}} \\
& K_{5}=\frac{q_{x} L}{\cos \beta}
\end{aligned}
$$

Define $H$ as the horizontal component of cable tension in mid-span; $L$ and $\beta$ are the distance and the slope angle of the line across two endpoints of the track cable. $Q$ and $q$ are the concentrated load and the uniform load imposed on the track cable in mid-span. $\mathrm{E}_{k}$ is the measured elastic modulus of steel wire rope. $\mathrm{Q}_{\mathrm{x}}, q_{\mathrm{x} 1}, q_{\mathrm{x} 2}$ and $q_{\mathrm{x} 3}$ are the concentrated load and the uniform load in the second state when the car moved from the tower of $x$. A and $\varepsilon$ are the cross-sectional area and the linear expansion coefficient of the steel wire rope.

\section{The Design of The Track Cable}

Defined $T_{\max }$ as the maximum tension of the track cable in mid-span, and its approximate value can be got from Equs.(3) (4) and (5), as following

$$
\begin{aligned}
& H_{\max }=\frac{q L^{2}}{8 f_{\max } \cos \beta}+\frac{Q_{\max } L}{4 f_{\max }} \\
& V=\frac{q L}{2 \cos \beta}+\frac{Q}{2} \pm H \operatorname{tg} \beta \\
& T_{\max }=\sqrt{H_{\max }^{2}+V^{2}}
\end{aligned}
$$

The maximum concentrated load $\mathrm{Q}_{\max }$ can be got from the lifting weight and the sling 
weight, and it has a value of $140 t$. The predetermined work sag $f_{\max }=71.4 \mathrm{~m}$. The uniform load imposed on the track cable in mid-span q=3.758 kN/m. From Equs.(3) (4) and (5), we can get $H_{\max }=19432.61 K N, V=3304.294 K N$ and $T_{\max }=19711.5 K N$. The number of track cable can be got, as following

$$
n>\frac{\mu T_{\max }}{[T]}=14.16
$$

Where $n$ is the number of track cable and take an integer for $15 .[T]=1670 \mathrm{kN}$ is the breaking force of the steel wire rope. $\mu=1.2$ is the dynamic amplification factor.

\section{The Calculation of The Erection Sag of The Track Cable}

When the the number of track cable is confirmed, the accurate value of $q$ can be got. Then the accurate value of $H_{\max }$ can be got from Equ.(3). Defined $H_{0}$ as the horizontal component of tension when the track cable in mid-span is in installation conditions. The erection sag of the track cable $f_{0}$ can be got from Equ.(3) when the values of the $Q$ and $H$ are confirmed. The difference between the theoretical and measured value can be shown as Tab.1.

Table 1. The erection sag of the track cable

\begin{tabular}{ccccc}
\hline & $f_{0}(\mathrm{~m})$ & Error $(\%)$ & $\mathrm{T}_{0}(K N)$ & Error $(\%)$ \\
\hline The theoretical value & 58.8 & -2.3 & 15346.7 & \multirow{2}{*}{2.4} \\
The measured value & 60.2 & & 14989.8 & \\
\hline
\end{tabular}

\section{The Design of The Hoisting Cable}

There are four root hoisting ropes. Defined $Q_{\mathrm{S}}$ as weight imposed on a piece of rope, and $Q_{\mathrm{S}}=$ $Q_{\max } / 4=35 t . S$ is the loading coefficient of the hoisting cable, and $\mathrm{S}=0.119$. The safety coefficient of the largest tensile of the hoisting cable can be got as following

$$
\frac{[T]}{Q_{S} S}=15.56>K=5
$$

Where $[T]$ is the breaking force of the hoisting cable, and its value is $648 \mathrm{KN}$.

\section{Conclusion}

The cable crane of the Jinsha river bridge is analyzed in this paper. Different from the traditional theory, the parabola theory of three spans is used in this paper. The track cable and the hoisting cable are designed based on the theory. The error between the theoretical value and the measured value meet the accuracy requirement of the construction.

\section{References}

[1] H.S. Xu, D.H. Yan, M.X. Ran, Design of load-bearing cable of cable crane used in large-span bridge construction, J. of Chongqing Jiaotong University, 28 (2009) 837-839.

[2] M.X. Ran, H.S. Xu, Mountain cable crane design key points of construction of long-span suspension bridge, The Chinese and foreign road, 29(4) (2009) 101-104.

[3] X.G. Li, M.S. Zhang, L. Lu, The installation technology of large-tonnage suspension bridge cable hoisting system, Highway, 4 (2017) 135-140.

[4] X.T. Deng, D.R. Zeng, Y.Q. Zhou, Finite element analysis of stability of cable-hoisting erection system of long-span arch bridge, J. of Chongqing Jiaotong University, 26 (2007) 3-7. 
[5] G.R. Zheng, The analysis of the mountains of long span suspension bridge stiffening girder construction process, Hunan Communication Sci. and Tec., 38 (2012) 78-79.

[6] W.D. Liu, Y. Liu, The design of mountains of long span suspension bridge cable hoisting system of construction, Highways and Automotive Applications, 128 (2008) 119-121.

[7] J. Yao, Z.Z. Zhuang, F.H. Zhang, The mountain steel truss stiffening girder installation technique of suspension bridges, Highway, 7 (2013) 82-87.

[8] S.Z. Yang, The conceptional design of main girder erection by cable-way for Egongyan suspension bridge in Chongqing, Municipal Eng. Tec. 23 (2005) 85-287. 